(2) Open Access Full Text Article

REVIEW

\title{
An appraisal of golimumab in the treatment of severe, active nonradiographic axial spondyloarthritis
}

This article was published in the following Dove Press journal:

Drug Design, Development and Therapy

II July 2016

Number of times this article has been viewed

\author{
Julien Paccou \\ René-Marc Flipo \\ Department of Rheumatology, Lille \\ University Hospital, Lille, France
}

Correspondence: Julien Paccou Department of Rheumatology, Lille University Hospital, Lille 2, 59037 Lille, France

Tel +33 320446926

Fax +33 320445462

Email julien.paccou@chru-lille.fr

\begin{abstract}
Golimumab (Simponi ${ }^{\circledR}$ ) is a fully human tumor necrosis factor $\alpha$ inhibitor (TNFi) antibody administered subcutaneously. In the European Union, golimumab is indicated for the treatment of adults with severe, active axial spondyloarthritis (axSpA), which includes both ankylosing spondylitis (AS) and nonradiographic axSpA (nr-axSpA). In the US, it is indicated for the treatment of adults with active AS only. This article reviews the efficacy and tolerability of golimumab in nr-axSpA patients compared to other TNFi agents (adalimumab, infliximab, etanercept, and certolizumab pegol). In one ongoing, well-designed controlled study (GOAHEAD), data at 16 weeks showed that treatment with golimumab (50 mg every 4 weeks) was effective in improving the clinical signs and symptoms of disease in nr-axSpA patients. In addition, 16 weeks of treatment with golimumab reduced inflammation in the sacroiliac joints and spine in patients with nr-axSpA. Moreover, objective evidence of active inflammation at baseline, such as a positive magnetic resonance imaging scan and/or an elevated CRP level, was a good predictor of treatment response to golimumab. Golimumab was generally well tolerated in this study, with a tolerability profile consistent with that seen in previous clinical trials for other indications. Although additional long-term data are needed, current evidence indicates that golimumab is an effective option for the treatment of nr-axSpA. However, in the absence of comparative head-to-head trials, there is no recommended hierarchy for the first prescription of a TNFi agent for the treatment of either nr-axSpA or AS.
\end{abstract}

Keywords: axial spondyloarthritis, nonradiographic axial spondyloarthritis, ankylosing spondylitis, golimumab, tumor necrosis factor $\alpha$ inhibitor, therapy

\section{Introduction}

The Assessment in Spondyloarthritis International Society (ASAS) has recently developed new criteria for the classification of spondyloarthritis ( $\mathrm{SpA}$ ) with the aim of achieving earlier diagnosis and in the process has introduced the concept of predominantly axial versus peripheral disease. ${ }^{1,2}$ Patients presenting with persisting back pain for $>3$ months and an age of onset $<45$ years are classified as having axial SpA (axSpA) in the presence of either sacroiliitis (on radiographs or magnetic resonance imaging [MRI] scans) and at least one additional typical SpA feature (imaging arm) or HLA-B27 positivity and two additional SpA characteristics (clinical arm). ${ }^{1}$ Depending on radiographic evidence indicating the presence or absence of permanent structural sacroiliac joint changes, patients are further classified as having either ankylosing spondylitis (AS) or nonradiographic axSpA (nr-axSpA). ${ }^{3}$

More recently, the American College of Rheumatology, the Spondylitis Association of America, and the Spondyloarthritis Research and Treatment Network teamed up 
to develop recommendations for the treatment of axSpA, which includes both AS and nr-axSpA. ${ }^{4}$ In adults with active AS and nr-axSpA, despite treatment with non-steroidal antiinflammatory drugs, they recommend treatment with tumor necrosis factor $\alpha$ inhibitors (TNFis) over no treatment with TNFi. ${ }^{4}$ However, in the USA, TNFis are indicated for the treatment of adults with active AS only, in accordance with the Food and Drug Administration decision not to approve TNFis for patients with nr-axSpA. ${ }^{5}$ Indeed, the Food and Drug Administration expressed doubts about the specificity of the ASAS criteria and the natural history of nr-axSpA, hinting that these patients may remit spontaneously and thus would not require treatment with TNFis. ${ }^{5}$ On the other hand, in the European Union (EU), TNFis are indicated for the treatment of adults with severe, active $\operatorname{axSpA}$, which includes both AS and nr-axSpA. Importantly, TNFis, such as golimumab, are indicated for the treatment of adults with severe, active nr-axSpA but with objective signs of inflammation as evidenced by MRI scans and/or elevated CRP levels. ${ }^{6}$

Many randomized, placebo-controlled clinical trials (RCTs) $)^{7-9}$ and retrospective studies ${ }^{10,11}$ have demonstrated the efficacy of TNFis in the treatment of AS. Five TNFis are currently used in the treatment of AS, ie, adalimumab, certolizumab, etanercept, golimumab, and infliximab. Moreover, biosimilars of infliximab and etanercept are now available for treatment of AS. ${ }^{12}$ The efficacy of these therapies has also been demonstrated in nr-axSpA patients in many $\mathrm{RCTs}^{13-18}$ and retrospective studies. ${ }^{19,20}$ In the EU, four TNFis are currently used in the treatment of nr-axSpA, ie, adalimumab, etanercept, certolizumab, and golimumab. TNFi biosimilar of etanercept is now available for treatment of nr-axSpA.

Golimumab - a human monoclonal antibody to TNF, which is administered subcutaneously at a dose of $50 \mathrm{mg}$ every 4 weeks - is approved for treating active AS. The results of the double-blind, randomized, placebo-controlled, Phase III GO-RAISE study have been previously reported. ${ }^{21}$ In that study, golimumab was evaluated in patients with active AS at week $24^{21}$ and week $104^{22}$ and on completion of the 5-year GO-RAISE trial. ${ }^{23}$ Regarding nr-axSpA, the results of the double-blind, randomized, placebo-controlled, Phase III GO-AHEAD study have been recently reported. ${ }^{18}$ In the EU, golimumab is the latest TNFi to have been approved for the treatment of nr-axSpA. ${ }^{6}$

\section{Objectives}

The aim of this study was to highlight the benefits and risks of golimumab compared to adalimumab, infliximab, etanercept, and certolizumab, in the treatment of severe, active nr-axSpA.

\section{Methods Types of studies}

We included RCTs.

\section{Types of participants}

We included studies of patients satisfying the ASAS classification criteria for nr-axSpA. ${ }^{1}$ We did not apply any additional restrictions in studies with regard to past medication comprising other TNFis.

\section{Types of interventions}

The following interventions were selected for inclusion:

1. adalimumab versus placebo,

2. infliximab versus placebo,

3. etanercept versus placebo,

4. certolizumab versus placebo,

5. golimumab versus placebo.

The following interventions were excluded:

1. etanercept versus sulfasalazine (ESTHER study), ${ }^{24}$

2. infliximab plus naproxen versus naproxen alone (INFAST study). ${ }^{25}$

\section{Selected outcome measures}

The following criteria were selected as the major outcome measures for this review:

1. ASAS20,

2. ASAS40,

3. ASAS partial remission,

4. BASDAI50,

5. MRI evidence of sacroiliitis,

6. improvement in BASDAI,

7. improvement in Bath Ankylosing Spondylitis Functional Index (BASFI).

An ASAS40 response was defined as a $\geq 40 \%$ improvement together with an absolute improvement from baseline of $\geq 2$ units (range $0-10$ ) in $\geq 3$ of the following four domains: patient global assessment of disease activity (0-10 cm visual analogue scale [VAS]), pain (total back pain, 0-10 cm VAS), function (BASFI, 0-10 cm VAS16), and inflammation/morning stiffness (mean score of items 5 and 6 of the BASDAI, 0-10 cm VAS), without any worsening in the remaining domain.

\section{Other measures}

Patients with and without objective signs of inflammation were also compared. Finally, the safety measurements reported in the selected studies were analyzed. 


\section{Results \\ Included studies}

Six trials with seven eligible treatment arms were available for patients with nr-axSpA. ${ }^{13-18}$ Further details on the included studies are provided in Table 1. One hundred thirteen patients received adalimumab across two studies, which included the ABILITY-1 study. ${ }^{13,15}$ Twelve patients received infliximab in one study. ${ }^{14}$ One hundred six patients received etanercept in one study. ${ }^{16}$ A study on certolizumab included both AS and nr-axSpA patients. Only the data from the nr-axSpA patients were used for this review. One hundred six nr-axSpA patients received certolizumab in the two arms of the study $(200 \mathrm{mg}$ and $400 \mathrm{mg}$ ). ${ }^{17}$ Ninety-eight patients received golimumab in the GO-AHEAD study. ${ }^{18}$ Previous exposure to TNFi was not permitted in three studies, ${ }^{15,16,18}$ whereas patients could have had TNFi prior to baseline in two studies. ${ }^{14,17}$ This information was not provided in the study performed by Haibel et al. ${ }^{13}$

\section{Participants}

Most participants were Caucasian in their thirties. Further details on the included studies are provided in Table 1. The percentage of female participants ranged from $25 \%$ to $62.2 \%$ in the treatment groups and from $25 \%$ to $57 \%$ in the control groups $(37.8 \%$ and $48 \%$, respectively in the GO-AHEAD study). The mean age ranged from 29.5 years to 38 years in the treatment groups and from 28.2 years to 39.9 years in the control groups ( 30.7 years and 31.7 years, respectively in the GO-AHEAD study). Between 59\% and $100 \%$ of the participants in the treatment groups were HLA-B27 positive, and a similar distribution was observed in the control groups $(74 \%-100 \%)(82.7 \%$ and $82 \%$, respectively in the GO-AHEAD study). The mean disease duration ranged from 1.4 years to 10.1 years in the treatment groups and from 1.1 years to 10.1 years in the control groups. No data were provided on mean disease duration in the GO-AHEAD study, but $68.4 \%$ of the participants in the golimumab group and $65 \%$ of the participants in the control group had a disease duration $<1$ year from diagnosis. The mean CRP ranged from $5 \mathrm{mg} / \mathrm{L}$ to $15 \mathrm{mg} / \mathrm{L}$ in the treatment groups and from $6.4 \mathrm{mg} / \mathrm{L}$ to $13 \mathrm{mg} / \mathrm{L}$ in the control groups $(15 \mathrm{mg} / \mathrm{L}$ and $13 \mathrm{mg} / \mathrm{L}$, respectively, in the GO-AHEAD study).

\section{Disease activity at baseline}

Further details on the included studies are provided in Table 2. All of the studies reported BASFI, BASDAI, and MRI evidence of sacroiliitis at baseline. The mean BASDAI ranged from 5.9 to 6.7 in the treatment groups and from

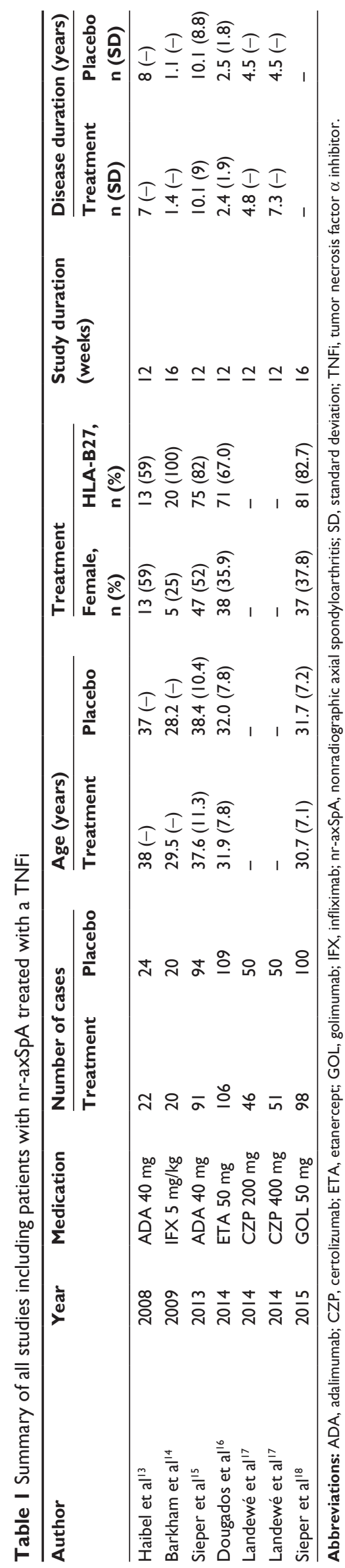



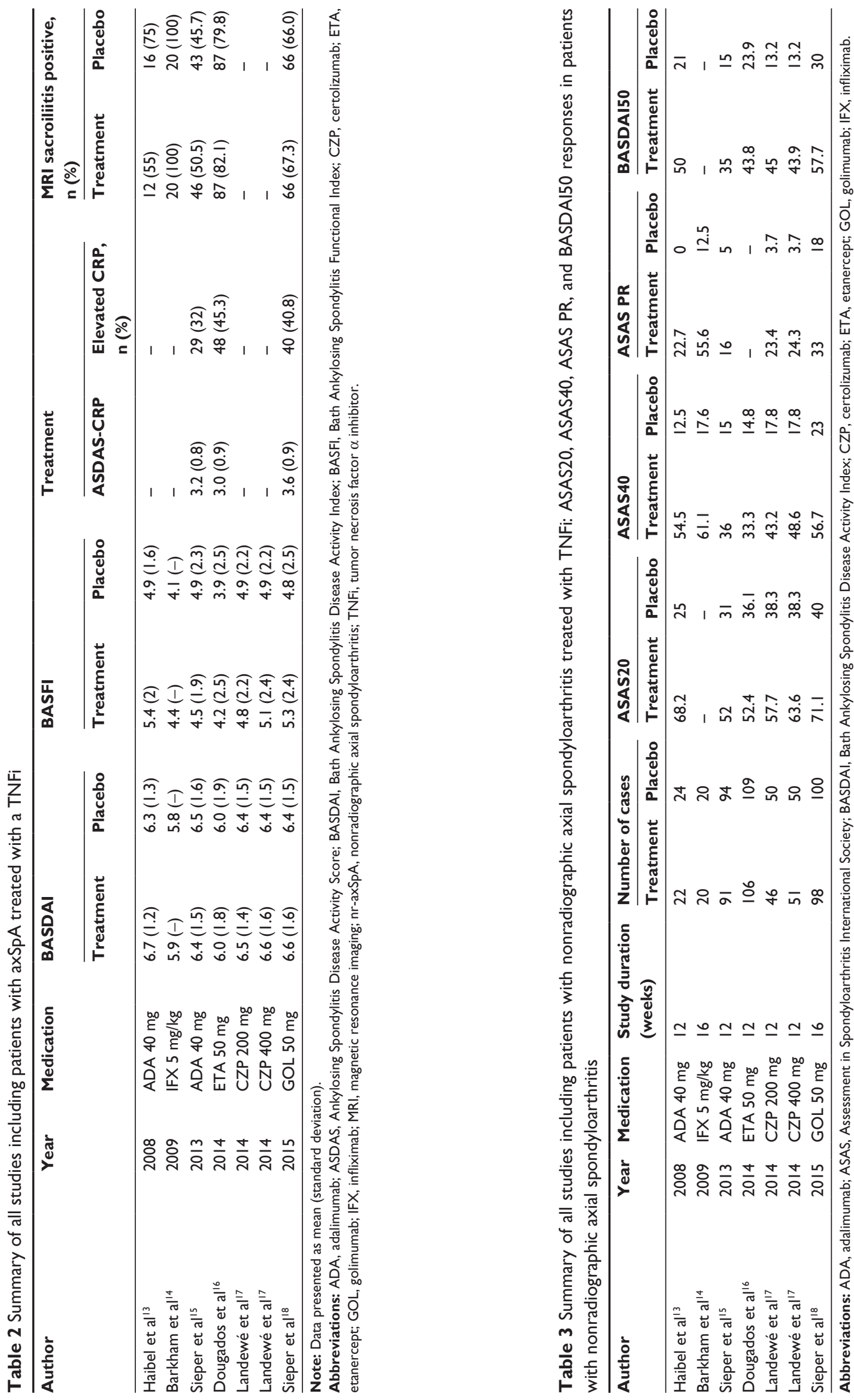
5.8 to 6.5 in the control groups (6.6 and 6.4, respectively, in the GO-AHEAD study). Between $50.5 \%$ and $100 \%$ of the participants in the treatment groups were MRI positive for sacroiliitis, and a similar distribution was observed in the control groups (45.7\%-100\%) (67.3\% and 66\%, respectively in the GO-AHEAD study).

\section{Major outcomes}

Further details on the included studies are provided in Table 3. The primary outcome was the ASAS20 response in two studies, ${ }^{17,18}$ which included the GO-AHEAD study, and the ASAS40 response in three studies. ${ }^{13,15,16}$ In Barkham et al, ${ }^{14}$ the primary outcome was the change in the total MRI score for sacroiliitis between baseline and week 16 .

Five studies ${ }^{13,15-18}$ reported an ASAS20 response after 12 weeks or 16 weeks of treatment with TNFi. In all studies, when TNFis were compared with placebo, statistically significant improvements in ASAS20 response were found (71.1\% versus $40 \%$ in the GO-AHEAD study). In the golimumab versus placebo intervention, the percentage of patients in the placebo group who achieved an ASAS20 response was relatively high ( $40 \%$ at 16 weeks), and the reason for this is unclear.
All studies ${ }^{13-18}$ reported an ASAS40 response after 12 weeks or 16 weeks of treatment with TNFi. In all studies, when TNFis were compared with placebo, statistically significant improvements in ASAS40 response were found (Figure 1) (56.7\% versus $23 \%$ in the GO-AHEAD study).

Five studies ${ }^{13,15-18}$ reported an ASAS partial remission after 12 weeks or 16 weeks of treatment with TNFi. In all studies, when TNFis were compared with placebo, statistically significant improvements in ASAS partial remission were found (33\% versus $18 \%$ in the GO-AHEAD study).

Five studies ${ }^{13,15-18}$ reported a BASDAI50 response after 12 weeks or 16 weeks of treatment with TNFi. In all studies, when TNFis were compared with placebo, statistically significant improvements in BASDAI50 response were found ( $57.7 \%$ versus $30 \%$ in the GO-AHEAD study).

Four studies ${ }^{14-16,18}$ reported a change in the total MRI score for sacroiliitis between baseline and week 12 or week 16 . In all studies, when TNFis were compared with placebo, statistically significant improvements in total MRI score for sacroiliitis were found. The mean change in the SPARCC (Spondyloarthritis Research Consortium of Canada) MRI SI joint score (0-72) revealed significant improvement in patients treated with golimumab (difference, golimumab

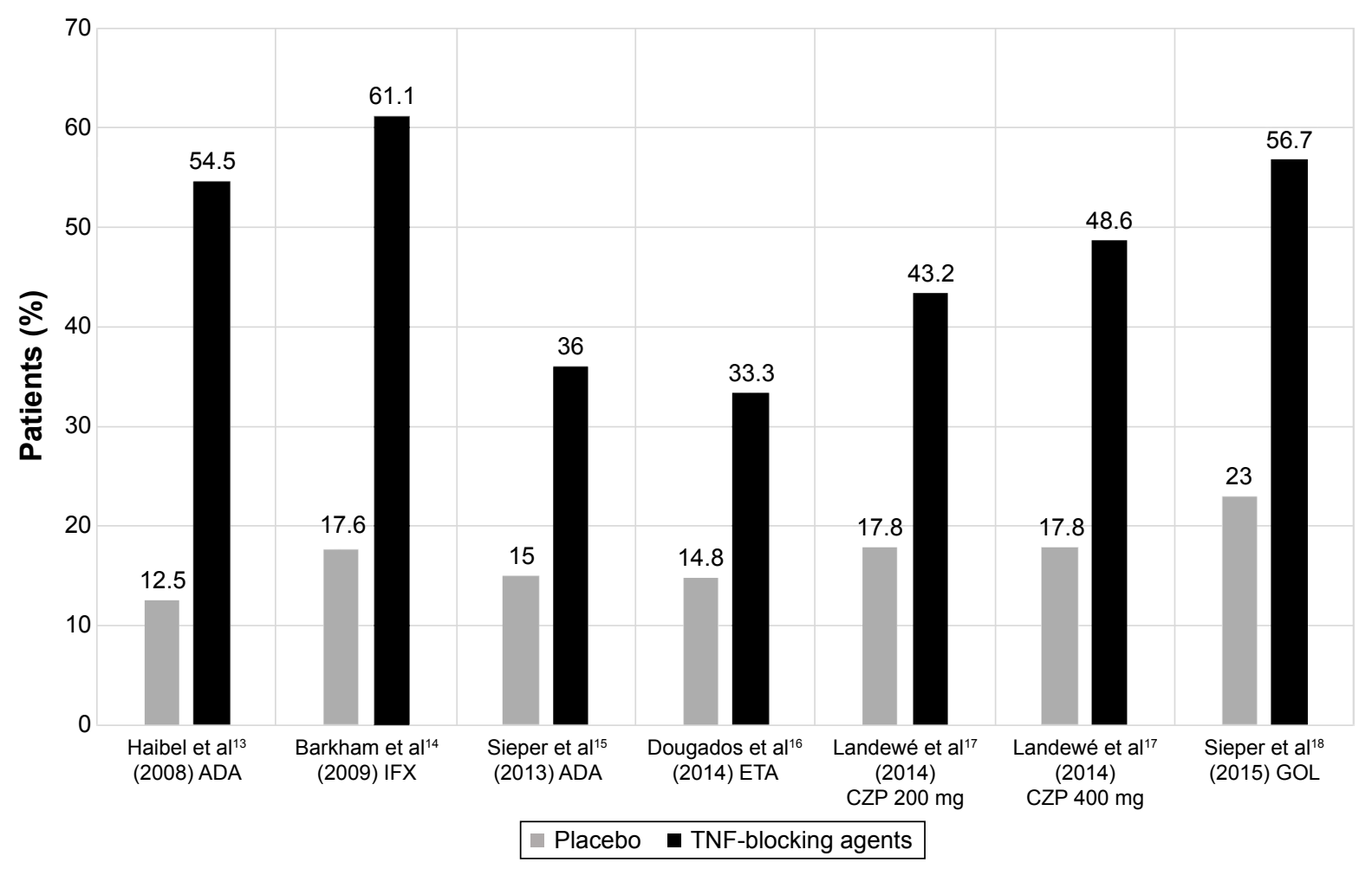

Figure I ASAS40 response in nr-axSpA patients after 12 (or 16) weeks of treatment with TNF-blocking agents.

Note: Different studies, no head-to-head comparison.

Abbreviations: ADA, adalimumab; ASAS, Assessment in Spondyloarthritis International Society; CZP, certolizumab; ETA, etanercept; GOL, golimumab; IFX, infliximab; $\mathrm{nr}$-axSpA, nonradiographic axial spondyloarthritis; TNF, tumor necrosis factor. 
versus placebo: $-4.3 ; P<0.0001$ ), adalimumab (difference, adalimumab versus placebo: $-2.6 ; P=0.003$ ), and etanercept (difference, etanercept versus placebo: $-3.0 ; P<0.001$ ). Moreover, the mean reduction in the total MRI score (0-24) from week 0 to week 16 was significantly greater in infliximab-treated patients compared with placebo-treated patients $(P=0.033)$.

Data on improvement in BASDAI and BASFI were available in all the studies. ${ }^{13-18}$ In the GO-AHEAD study, the difference in golimumab versus placebo was $-2.00(-2.68,-1.35)$, with $P<0.0001$ for BASDAI, and $-2.73(-2.33,-1.13)$, with $P<0.0001$ for BASFI.

\section{Comparison of patients with and without objective signs of inflammation}

Patients with objective signs of inflammation (OSI) were defined by the presence of sacroiliitis as evidenced by MRI and/or an elevated CRP level. In patients with OSI, golimumab had a robust treatment effect: $76.9 \%$ of these patients achieved an ASAS20 response at week 16 compared with $37.5 \%$ in the placebo group. In patients without OSI, there were no differences in the efficacy end points (ASAS20 and ASAS40 responses), indicating that this subgroup of nr-axSpA patients may not be suitable candidates for treatment with golimumab, as was also recently shown for the treatment of nr-axSpA with adalimumab and etanercept. ${ }^{15,16}$

\section{Safety}

Overall, golimumab was well tolerated: the incidence of serious adverse effects and other significant AEs was comparable between patients treated with golimumab and those treated with placebo. No new safety signals were identified during the treatment of nr-axSpA with TNFi (Table 4).

\section{Conclusion}

These results demonstrated that golimumab, administered subcutaneously every 4 weeks, is efficacious and generally well tolerated in patients with nr-axSpA. Golimumab treatment led to a rapid reduction in the signs and symptoms of nr-axSpA, and this effect was sustained through week 16 . Thus, objective evidence of active inflammation at baseline, such as a positive MRI scan and/or an elevated CRP level, seems to be a good predictor of treatment response to TNFis.

Although additional long-term data are needed, and current evidence indicates that golimumab is an effective option for the treatment of nr-axSpA. However, in the absence of comparative head-to-head trials, there is no recommended hierarchy for the first prescription of a TNFi agent for the treatment of either nr-axSpA or AS.

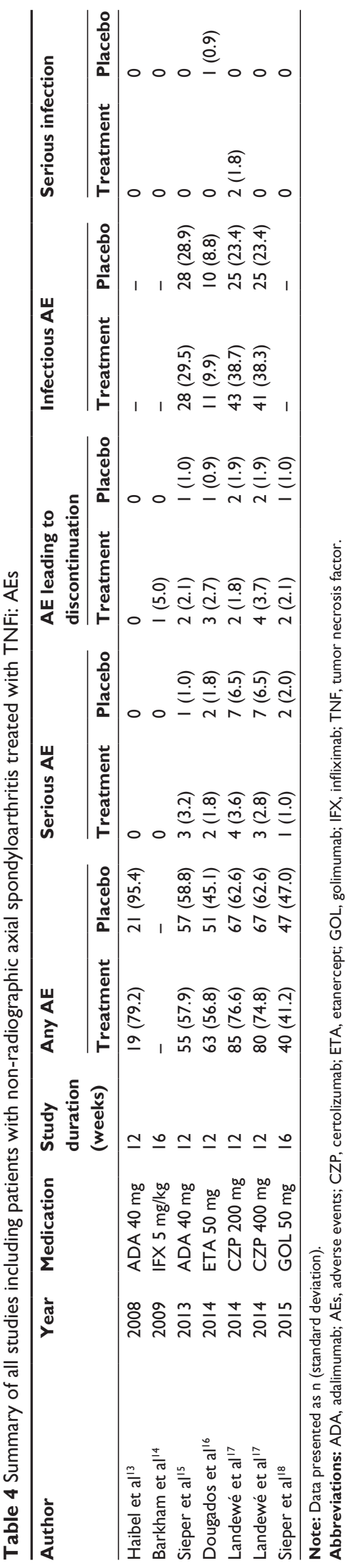




\section{Perspectives}

Recently, Deodhar et $\mathrm{al}^{26}$ highlighted that AS and nr-axSpA represent the ends of the spectrum of axSpA, which should be considered as a single process, and proposed that RCTs designed to obtain regulatory approval for drugs be conducted in patients across the entire spectrum of axSpA. Furthermore, if the aim of a clinical trial is to treat patients with axSpA early in the course of their disease, the duration of symptoms should be more important inclusion criteria than the presence (AS) or absence of definite sacroiliitis (nr-axSpA).

Another challenge would be to investigate whether patients with nr-axSpA can achieve a state of drug-free remission. Indeed, the European Medical Agency has requested a "withdrawal" trial design, in which patients with nr-axSpA in remission for a predefined duration of time are randomized to receive either placebo or active study agent.

\section{Disclosure}

The authors report no conflicts of interest in this work.

\section{References}

1. Rudwaleit M, Landewé R, van der Heijde D, et al. The development of assessment of SpondyloArthritis International Society classification criteria for axial spondyloarthritis (part I): classification of paper patients by expert opinion including uncertainty appraisal. Ann Rheum Dis. 2009;68:770-776.

2. Rudwaleit M, van der Heijde D, Landewé R, et al. The Assessment of SpondyloArthritis International Society classification criteria for peripheral spondyloarthritis and for spondyloarthritis in general. Ann Rheum Dis. 2011;70:25-31.

3. Sieper J, van der Heijde D. Non-radiographic axial spondyloarthritis: new definition of an old disease? Arthritis Rheum. 2013;65:543-551.

4. Ward MM, Deodhar A, Akl EA, et al. American College of Rheumatology/Spondylitis Association of America/Spondyloarthritis Research and Treatment Network 2015 Recommendations for the treatment of ankylosing spondylitis and nonradiographic axial spondyloarthritis. Arthritis Rheumatol. 2016;68:282-298.

5. Deodhar A, Reveille JD, van den Bosch F, et al. The concept of axial spondyloarthritis: joint statement of the spondyloarthritis research and treatment network and the assessment of SpondyloArthritis international society in response to the US Food and Drug Administration's comments and concerns. Arthritis Rheumatol. 2014;66:2649-2656.

6. European Medicines Agency [webpage on the Internet]. Committee for Medicinal Products for Human Use. 2015. Summary of opinion (post authorisation): Simponi (golimumab); 2015. Available from: http://www. ema.europa.eu/docs/en_GB/document_library/Summary_of_opinion/ human/000992/WC500187055.pdf. Accessed May 21, 2015.

7. van der Heijde D, Dijkmans B, Geusens P, et al. Ankylosing spondylitis study for the evaluation of recombinant infliximab therapy study group. Efficacy and safety of infliximab in patients with ankylosing spondylitis: results of a randomized, placebo-controlled trial (ASSERT). Arthritis Rheum. 2005;52:582-591.

8. van der Heijde D, Kivitz A, Schiff MH, et al; ATLAS Study Group. Efficacy and safety of adalimumab in patients with ankylosing spondylitis: results of a multicenter, randomized, double-blind, placebo-controlled trial. Arthritis Rheum. 2006;54:2136-2146.

9. Calin A, Dijkmans BA, Emery P, et al. Outcomes of a multicentre randomised clinical trial of etanercept to treat ankylosing spondylitis. Ann Rheum Dis. 2004;63:1594-1600.
10. Lorenzin M, Ortolan A, Frallonardo P, Oliviero F, Punzi L, Ramonda R. Predictors of response and drug survival in ankylosing spondylitis patients treated with infliximab. BMC Musculoskelet Disord. 2015; $16: 166$.

11. Spadaro A, Lubrano E, Marchesoni A, et al. Remission in ankylosing spondylitis treated with anti-TNF- $\alpha$ drugs: a national multicentre study. Rheumatology (Oxford). 2013;52:1914-1919.

12. Park W, Yoo DH, Jaworski J, et al. Comparable long-term efficacy, as assessed by patient-reported outcomes, safety and pharmacokinetics, of CT-P13 and reference infliximab in patients with ankylosing spondylitis: 54-week results from the randomized, parallel-group PLANETAS study. Arthritis Res Ther. 2016;18:25.

13. Haibel H, Rudwaleit M, Listing J, et al. Efficacy of adalimumab in the treatment of axial spondylarthritis without radiographically defined sacroiliitis: results of a twelve-week randomized, double-blind, placebocontrolled trial followed by an open-label extension up to week fiftytwo. Arthritis Rheum. 2008;58:1981-1991.

14. Barkham N, Keen HI, Coates LC, et al. Clinical and imaging efficacy of infliximab in HLA-B27-positive patients with magnetic resonance imaging-determined early sacroiliitis. Arthritis Rheum. 2009; 60:946-954

15. Sieper J, van der Heijde D, Dougados M, et al. Efficacy and safety of adalimumab in patients with non-radiographic axial spondyloarthritis: results of a randomised placebo-controlled trial (ABILITY-1). Ann Rheum Dis. 2013;72:815-822.

16. Dougados M, van der Heijde D, Sieper J, et al. Symptomatic efficacy of etanercept and its effects on objective signs of inflammation in early nonradiographic axial spondyloarthritis: a multicenter, randomized, double-blind, placebo-controlled trial. Arthritis Rheumatol. 2014;66:2091-2102.

17. Landewé R, Braun J, Deodhar A, et al. Efficacy of certolizumab pegol on signs and symptoms of axial spondyloarthritis including ankylosing spondylitis: 24-week results of a double-blind randomised placebocontrolled phase 3 study. Ann Rheum Dis. 2014;73:39-47.

18. Sieper J, van der Heijde D, Dougados M, et al. A randomized, doubleblind, placebo-controlled, sixteen-week study of subcutaneous golimumab in patients with active nonradiographic axial spondyloarthritis. Arthritis Rheumatol. 2015;67:2702-2712.

19. Lubrano E, Perrotta FM, Marchesoni A, et al. Remission in nonradiographic axial spondyloarthritis treated with anti-tumor necrosis factor- $\alpha$ drugs: an Italian multicenter study. J Rheumatol. 2015;42:258-263.

20. Corli J, Flipo RM, Philippe P, et al. Tumor necrosis factor- $\alpha$ inhibition in ankylosing spondylitis and nonradiographic axial spondyloarthritis: treatment response, drug survival, and patient outcome. J Rheumatol. 2015;42:2376-2382.

21. Inman RD, Davis JC Jr, Heijde DV, et al. Efficacy and safety of golimumab in patients with ankylosing spondylitis: results of a randomized, double-blind, placebo-controlled, phase III trial. Arthritis Rheum. 2008;58:3402-3412.

22. van der Heijde D, Deodhar A, Braun J, et al; GO-RAISE Investigators. The effect of golimumab therapy on disease activity and health-related quality of life in patients with ankylosing spondylitis: 2-year results of the GO-RAISE trial. J Rheumatol. 2014;41:1095-1103.

23. Deodhar A, Braun J, Inman RD, et al. Golimumab administered subcutaneously every 4 weeks in ankylosing spondylitis: 5-year results of the GO-RAISE study. Ann Rheum Dis. 2015;74:757-761.

24. Song IH, Weiß A, Hermann KG, et al. Similar response rates in patients with ankylosing spondylitis and non-radiographic axial spondyloarthritis after 1 year of treatment with etanercept: results from the ESTHER trial. Ann Rheum Dis. 2013;72:823-825.

25. Sieper J, Lenaerts J, Wollenhaupt J, et al. Efficacy and safety of infliximab plus naproxen versus naproxen alone in patients with early, active axial spondyloarthritis: results from the double-blind, placebocontrolled INFAST study, part 1. Ann Rheum Dis. 2014;73:101-107.

26. Deodhar A, Strand V, Kay J, Braun J. The term non-radiographic axial spondyloarthritis is much more important to classify to diagnose patient with axial spondyloarthritis. Ann Rheum Dis. 2016;75:791-794. 


\section{Publish your work in this journal}

Drug Design, Development and Therapy is an international, peerreviewed open-access journal that spans the spectrum of drug design and development through to clinical applications. Clinical outcomes, patient safety, and programs for the development and effective, safe, and sustained use of medicines are a feature of the journal, which

has also been accepted for indexing on PubMed Central. The manuscript management system is completely online and includes a very quick and fair peer-review system, which is all easy to use. Visit http://www.dovepress.com/testimonials.php to read real quotes from published authors.

Submit your manuscript here: http://www.dovepress.com/drug-design-development-and-therapy-journal 